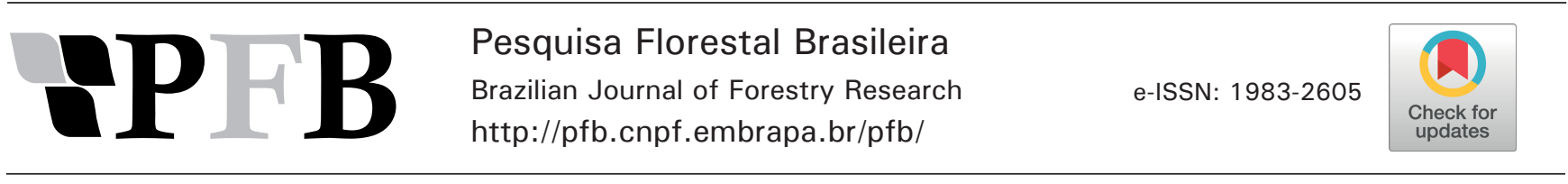

\title{
Propriedades energéticas da madeira e do carvão vegetal de Cenostigma macrophyllum: subsídios ao uso sustentável
} \author{
Maria Fernanda Vieira Rocha1 ${ }^{1}$, Paulo Fernando Trugilho' ${ }^{1}$ (D) \\ ${ }^{11}$ Universidade Federal de Lavras, Campus Universitário, CP. 3037, CEP 37200-000, Lavras, MG, Brasil \\ ${ }^{2}$ Universidade Federal de Viçosa, Av. Peter Henry Rolfs, s/n, Campus Universitário, CEP 36570-000, Viçosa, MG, Brasil \\ ${ }^{3}$ Universidade Federal do Piauí, BR 135, Km 03, Planalto Horizonte, Cibrazen, CEP 64900-000, Bom Jesus, PI, Brasil
}

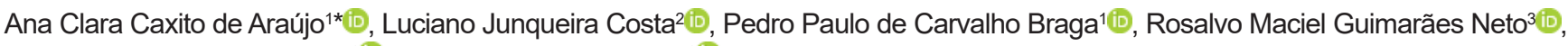

"Autor correspondente:
anacaxitoengflor@hotmail.com

Termos para indexação:

Temperatura de carbonização

Rendimento gravimétrico

Termogravimetria

Index terms:

Carbonization temperature

Gravimetric yield

Thermogravimetry

Histórico do artigo:

Recebido em 28/11/2017

Aprovado em 21/05/2018

Publicado em 11/07/2018

doi: 10.4336/2018.pfb.38e201701546

\begin{abstract}
Resumo - O objetivo deste estudo foi avaliar a qualidade da madeira de Cenostigma macrophyllum Tul para uso energético e determinar os rendimentos e propriedades do carvão vegetal produzido em diferentes temperaturas de carbonização. Foram retirados discos de $3 \mathrm{~cm}$ de espessura nas posições basal, $25 \%, 50 \%, 75 \%$ e $100 \%$ da altura comercial do fuste. Os discos foram cortados em cunhas e metade destas foi utilizada para análises na madeira e a outra metade foi carbonizada em temperaturas finais de $400{ }^{\circ} \mathrm{C}, 500{ }^{\circ} \mathrm{C}$ e $600{ }^{\circ} \mathrm{C}$ para avaliação dos rendimentos e características do biorredutor. A densidade básica $\left(1,2 \mathrm{~g} \mathrm{~cm}^{-3}\right)$, teor de lignina (34\%), poder calorífico superior $\left(4.845 \mathrm{cal} \mathrm{g}^{-1}\right)$ e rendimento gravimétrico de carbonização (RGC) aos $400^{\circ} \mathrm{C}(41,5 \%)$ da madeira do caneleiro se destacaram. O aumento da temperatura de pirólise da madeira de $400{ }^{\circ} \mathrm{C}$ para $600{ }^{\circ} \mathrm{C}$ resultou em acréscimo de $29,4 \%$ do teor de carbono fixo e redução de $19 \%$ e $63,4 \%$, respectivamente, do RGC e do teor de materiais voláteis do carvão vegetal. Conclui-se que a espécie apresentou valores satisfatórios para produção energética.
\end{abstract}

\section{Wood and charcoal energy properties of Cenostigma macrophyllum: subsidies to sustainable use}

\begin{abstract}
This study aimed to evaluate the quality Cenostigma macrophyllum Tul wood for energetic use and to determine the yields and charcoal properties produced at different carbonization temperatures. Discs with $3 \mathrm{~cm}$ of thickness were obtained from stem basal positions, $25 \%, 50 \%, 75 \%$ and $100 \%$ of commercial height. The discs were split in two parts. One was used to determine wood properties and the other was carbonized at final temperatures of $400{ }^{\circ} \mathrm{C}, 500{ }^{\circ} \mathrm{C}$ and $600{ }^{\circ} \mathrm{C}$ for bio-reducer evaluation . Basic density $\left(1.2 \mathrm{~g} \mathrm{~cm}^{-3}\right)$, lignin content $(34 \%)$, higher calorific value $\left(4,845 \mathrm{cal} \mathrm{g}^{-1}\right)$ and gravimetric yield in charcoal (GYC) at $400{ }^{\circ} \mathrm{C}(41.5 \%)$ were the highlights. The increase of wood pyrolysis temperature from $400{ }^{\circ} \mathrm{C}$ to $600{ }^{\circ} \mathrm{C}$ resulted in $29.4 \%$ increase in fixed carbon content and a reduction of $19 \%$ and $63.4 \%$, respectively, in charcoal GYC and volatile matter content. In general, the species presented satisfactory energy production.
\end{abstract}

\section{Introdução}

As principais espécies cultivadas no Brasil para uso energético pertencem ao gênero Eucalyptus (Indústria Brasileira de Árvores, 2017). Esta ampla utilização se deve à adaptação destas espécies aos diferentes climas existentes no país e, consequentemente, elevadas produtividades e adequados índices de qualidade da madeira para uso energético. Ainda que pesquisas de melhoramento genético deste gênero tenham desenvolvido clones mais adaptados às condições de estresse hídrico (Freitas et al., 2015; Castro et al., 
2017), como as que ocorrem no semiárido brasileiro, a produtividade destes plantios é, por vezes, inferior ao seu potencial produtivo e apresentam elevada mortalidade devido à baixa pluviosidade. Estudos sobre a vegetação nativa da região, já naturalmente adaptada às condições de restrição hídrica, podem revelar espécies arbóreas promissoras para geração de bioenergia e com possibilidades concretas de diversificação da silvicultura brasileira.

Cenostigma macrophyllum é uma espécie que possui hábito arbustivo ou arbóreo, conhecida popularmente como caneleiro, e é relativamente comum do centro-sul do Piauí (Queiroz, 2009). As árvores podem atingir até 20 $\mathrm{m}$ de altura e possuem tronco sulcado, ereto e cilíndrico (Machado et al., 2006). Com o decreto municipal $n^{\circ}$ 2.407, de 13 de agosto de 1993, o caneleiro tornou-se símbolo da capital Teresina, PI (Teresina, 1993).

A utilização da madeira do caneleiro, como lenha ou para produção de carvão vegetal, seja para o consumo doméstico, comercial ou industrial é realizado tradicionalmente, mesmo sem se conhecer as características tecnológicas da madeira. Os estudos que avaliam o potencial das espécies alternativas localizadas em áreas de manejo florestal, visando à sua utilização energética, podem ser uma solução para minimizar impactos e assegurar a sustentabilidade, além da fonte de renda para produtores rurais, contribuindo para o desenvolvimento socioeconômico e ambiental, da região nordeste do Brasil (Santos et al., 2013).

Assim, é indispensável determinar as propriedades físicas e químicas que se relacionam com o desempenho energético da biomassa, tais como densidade básica, teor de lignina, holocelulose, extrativos, cinzas e poder calorífico superior (Soares et al., 2014; Santos et al., 2016). O elevado conteúdo de lignina e a qualidade desta macromolécula podem contribuir para maiores rendimentos durante a pirólise (Pereira et al., 2013b; Araújo et al., 2016). O teor de extrativos solúveis em etanol da madeira também representa uma característica importante para a decomposição térmica do lenho. A redução destes compostos diminui o rendimento do carvão vegetal e provoca deslocamento da curva termogravimétrica em direção a temperaturas mais altas (Sebio-Punhal et al., 2012).

As propriedades físicas, químicas, anatômicas e mecânicas do carvão vegetal são afetadas, basicamente, pelas características intrínsecas da matéria prima que o originou, pelos parâmetros de carbonização (temperatura, tempo e taxa de aquecimento) e, também, pelos sistemas de produção (Bailis et al., 2013). Entre os parâmetros de pirólise, a temperatura influencia fortemente as características térmicas e químicas da fração sólida resultante (Ghani et al., 2013).

No Brasil, cerca de $60 \%$ a $80 \%$ da produção de carvão vegetal é realizada em fornos rudimentares de alvenaria. Esses apresentam capacidade limitada de processamento e controle dos parâmetros de carbonização, o que resulta em variações consideráveis da temperatura durante a pirólise da madeira (Oliveira et al., 2013).

A temperatura final de carbonização influencia o rendimento das frações sólida, líquida e gasosa deste processo, além de apresentar efeitos sobre as propriedades físicas, químicas e energéticas do carvão vegetal, como sobre a densidade, o teor de materiais voláteis, de cinzas, e de carbono fixo e sobre o poder calorífico superior. Consequentemente, é um importante parâmetro para definir a qualidade deste combustível sólido (Trugilho \& Silva, 2001; Vilas Boas et al., 2010; Azevedo et al., 2013; Couto et al., 2015; Vieira et al., 2016).

Diante do exposto, objetivou-se determinar as propriedades físicas, químicas e energéticas da madeira de Cenostigma macrophyllum Tul relacionadas à produção de energia térmica e avaliar a qualidade do carvão vegetal produzido em diferentes temperaturas de pirólise.

\section{Material e métodos}

\section{Biomassa vegetal}

O estudo foi realizado com madeira de Cenostigma macrophyllum Tul (caneleiro) coletada em uma área de vegetação nativa, submetida a um plano de manejo florestal sustentável e localizada no município de Cristino Castro, PI. O projeto implementado nessa área visa produzir 1.091.700 st de lenha por meio da exploração sustentável de 3.639 ha, com produtividade média de $300 \mathrm{st} \mathrm{ha}^{-1}$, num ciclo de corte de 13 anos, por meio de talhadia simples (corte raso sem destoca e sem fogo) da vegetação lenhosa em área não contínua (Neves \& Neves, 2008).

Por se tratar de uma população inequiânea estabelecida em uma extensa área manejada e considerando que a idade do material vegetal, o relevo e o solo são fatores que podem alterar as características químicas da madeira, a amostragem foi limitada quanto ao número de indivíduos, buscando-se maior homogeneidade das 
fontes de variação. Portanto, foram selecionadas para este trabalho duas árvores e os indivíduos amostrados foram aqueles que apresentaram diâmetro semelhante, boas condições fitossanitárias, proximidade entre fustes (distância de aproximadamente $3 \mathrm{~m}$ ) e características fenotípicas semelhantes. As árvores apresentavam 13, 6 cm e 9,0 m (árv.1) e 11,5 cm e 8,0 m (árv. 2) de diâmetro a 1,30 m do solo (DAP) e altura total, respectivamente.

De cada árvore, foram retirados discos de aproximadamente $5 \mathrm{~cm}$ de espessura nas posições da base $(0 \%), 25 \%, 50 \% 75 \%$ e $100 \%$ da altura comercial do fuste, considerada até o diâmetro mínimo de $5 \mathrm{~cm}$. Os discos foram seccionados em 4 cunhas, passando pela medula, sendo duas utilizadas para carbonização e as outras duas para análises químicas e energética da madeira.

\section{Caracterização da madeira}

A densidade básica da madeira foi determinada pelo método de imersão, conforme a norma NBR 11941 (Associação Brasileira de Normas Técnicas, 2003) e o poder calorífico superior foi determinado em calorímetro digital, conforme a NBR 8633 (Associação Brasileira de Normas Técnicas, 1984).

A composição química foi realizada a partir da determinação dos teores de: extrativos, de acordo com a norma NBR 14660 (Associação Brasileira de Normas Técnicas, 2004); teor de lignina insolúvel (Klason), determinado de acordo com a metodologia proposta por Gomide \& Demuner (1986), e teor de lignina solúvel (Klason) em ácido sulfúrico, determinado de acordo com a metodologia proposta por Goldschimid (1971), sendo o teor de lignina total a soma da lignina solúvel e insolúvel.

Os ensaios foram realizados em duplicata, sendo utilizada amostra composta pelas seis posições longitudinais de amostragem do fuste.

A análise termogravimétrica foi realizada sob atmosfera de $\mathrm{N}_{2}$ em equipamento Shimadzu TGA-60, a uma vazão constante de $50 \mathrm{~mL} \mathrm{~min}^{-1}$ e razão de aquecimento de $10{ }^{\circ} \mathrm{C} \mathrm{min}{ }^{-1}$. Foram utilizadas $\pm 4 \mathrm{mg}$ de serragem de madeira com granulometria entre 200 mesh e 270 mesh (American Society for Testing and Materials, 1982). Os termogramas foram obtidos a partir da temperatura ambiente, em torno de $25{ }^{\circ} \mathrm{C}$, até temperatura máxima de $700{ }^{\circ} \mathrm{C}$ e as curvas termogravimétrica e derivada da curva termogravimétrica foram geradas considerando como $100 \%$ a massa seca da amostra.
Procedeu-se, sob as mesmas condições de análise, a termogravimetria da madeira de Eucalyptus sp. (espécies mais utilizadas para fins energéticos no Brasil), para efeito de comparação com a madeira em estudo.

\section{Carbonização e avaliação do carvão vegetal}

As carbonizações foram realizadas em forno elétrico do tipo mufla com sistema de condensação de gases. Utilizou-se a taxa de aquecimento de $100{ }^{\circ} \mathrm{C} \mathrm{h}^{-1}$ até as temperaturas finais de carbonização de $400{ }^{\circ} \mathrm{C}, 500{ }^{\circ} \mathrm{C}$ e $600^{\circ} \mathrm{C}$, com tempo de residência à temperatura máxima de 30 min para todas as metodologias de carbonização.

Após cada tratamento térmico, foram determinados, tendo como referência a madeira seca, os rendimentos gravimétricos de carvão vegetal, líquido pirolenhoso e, por diferença, o gás não condensável.

A análise química imediata do carvão vegetal foi determinada de acordo com a NBR 8112 (Associação Brasileira de Normas Técnicas, 1986). A densidade relativa aparente foi determinada por meio do método de imersão em água e o poder calorífico superior do carvão vegetal foi mensurado de acordo com a NBR 8633 (Associação Brasileira de Normas Técnicas, 1984).

\section{Resultados}

A madeira de Cenostigma macrophyllum apresentou densidade básica de 1,200 g. $\mathrm{cm}^{-3}$, sendo classificada como madeira de alta densidade. O teor de lignina encontrado foi de $34 \%$ da massa seca inicial da madeira livre de extrativos, enquanto que o teor de extrativos totais foi de cerca de $9 \%$ da massa seca da madeira. O poder calorífico superior (PCS) foi da ordem de $4.845 \mathrm{cal} \mathrm{g}^{-1}$, valor satisfatório para produção de energia calorífica.

Verificou-se acréscimo dos valores de rendimento gravimétrico em gases não condensáveis (RGNC), teor de carbono fixo (TCF) e poder calorífico superior (PCS) do carvão vegetal com o aumento da temperatura final de pirólise. Comportamento inverso foi observado para o rendimento gravimétrico (RGC) e teor de materiais voláteis (TMV) do carvão vegetal (Tabela 1).

O RGC apresentou tendência de redução com a elevação da temperatura de pirólise, reduzindo, aproximadamente, $19 \%$ da massa residual entre $400{ }^{\circ} \mathrm{C}$ e $600{ }^{\circ} \mathrm{C}$. Aos $400{ }^{\circ} \mathrm{C}$, temperatura próxima daquela utilizada na produção industrial de carvão vegetal, o rendimento médio da fração sólida foi de $41,53 \%$. 
Tabela 1. Rendimentos e qualidade do carvão vegetal de Cenostigma macrophyllum produzido a diferentes temperaturas.

\begin{tabular}{cccc}
\hline $\begin{array}{c}\text { Temperatura } \\
\text { Variável }\end{array}$ & $\mathbf{4 0 0}^{\circ} \mathbf{C}$ & $\mathbf{5 0 0}^{\circ} \mathbf{C}$ & $\mathbf{6 0 0}^{\circ} \mathbf{C}$ \\
\hline RGC (\%) & $41,53 \pm 1,55$ & $36,00 \pm 1,07$ & $34,82 \pm 3,55$ \\
RGLP (\%) & $38,06 \pm 2,60$ & $38,66 \pm 5,05$ & $36,07 \pm 10,79$ \\
RGNC (\%) & $20,40 \pm 1,05$ & $25,34 \pm 3.98$ & $29,11 \pm 7,24$ \\
TMV (\%) & $30,13 \pm 1,71$ & $20,24 \pm 0,66$ & $10,90 \pm 0,82$ \\
Cz (\%) & $2,22 \pm 0,58$ & $1,58 \pm 0,07$ & $1,60 \pm 0,62$ \\
TCF (\%) & $67,64 \pm 2,29$ & $78,17 \pm 0,73$ & $87,50 \pm 1,45$ \\
Da (g.cm-3) & $0,546 \pm 0,028$ & $0,550 \pm 0,011$ & $0,555 \pm 0,033$ \\
PCS (cal.g $\left.{ }^{-1}\right)$ & $7.183 \pm 188,44$ & $7.771 \pm 61,87$ & $8.111 \pm 68,24$ \\
\hline
\end{tabular}

$\mathrm{RGC}=$ rendimento gravimétrico em carvão; $\mathrm{RGLP}=$ rendimento gravimétrico em líquido pirolenhoso; $\mathrm{RGNC}=$ rendimento dos gases não condensáveis; $\mathrm{TMV}=$ materiais voláteis; $\mathrm{Cz}=$ teor de cinzas; $\mathrm{TCF}=$ teor de carbono fixo; $\mathrm{Da}=$ densidade aparente; $\mathrm{PCS}=$ poder calorífico superior.

O TMV apresentou redução de $63,4 \%$ entre $400{ }^{\circ} \mathrm{C}$ e $600{ }^{\circ} \mathrm{C}$. Resultado contrário foi observado para o teor de carbono fixo, em que o aumento da temperatura de pirólise da madeira ocasionou acréscimo de 29,4\% nos valores. O poder calorífico superior foi afetado pela temperatura final de carbonização, apresentando aumento de $12,9 \%$ entre $400{ }^{\circ} \mathrm{C}$ e $600{ }^{\circ} \mathrm{C}$.

$\mathrm{Na}$ análise termogravimétrica foram observadas cinco faixas distintas quanto à perda de massa da madeira (Figura 1). A primeira corresponde ao processo de perda de umidade da amostra (5,17\% da massa inicial) e ocorre do início da análise até aproximadamente $100{ }^{\circ} \mathrm{C}$ (Figura 1 - F1). A partir desta temperatura, a massa se mantém praticamente constante até os $210^{\circ} \mathrm{C}$, onde se inicia a decomposição térmica dos componentes químicos da madeira (Figura 1- F2).

Entre $200{ }^{\circ} \mathrm{C}$ e $500{ }^{\circ} \mathrm{C}$ verificam-se dois picos na derivada da curva termogravimétrica (DTG), onde a velocidade de perda de massa ocorre de forma mais acentuada. $\mathrm{O}$ primeiro pico foi observado entre $210^{\circ} \mathrm{C}$ e $315^{\circ} \mathrm{C}$, sendo relativo à decomposição das hemiceluloses (Figura 1- F3). Neste intervalo perdeuse $24,75 \%$ da massa da madeira (Tabela 2 ). O segundo

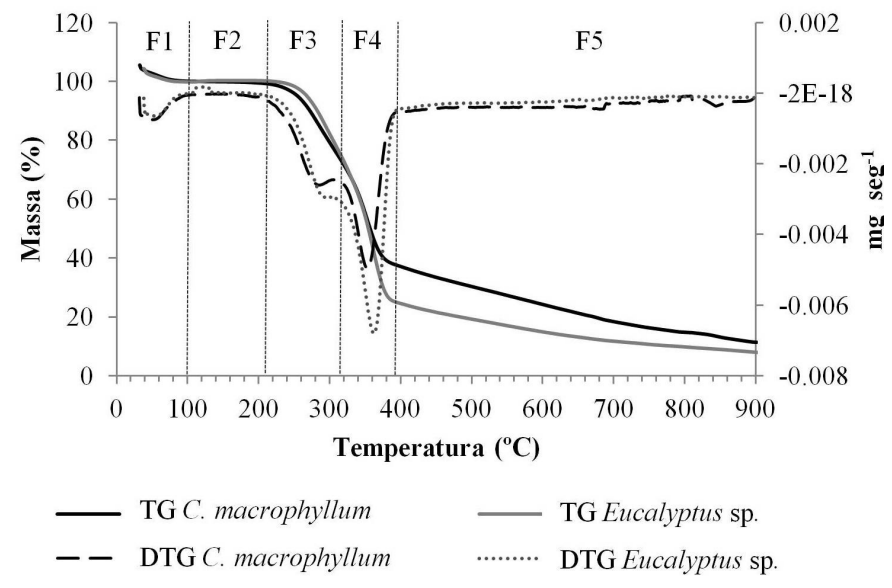

Figura 1. Curva termogravimétrica (TG) e termogravimétrica derivada (DTG) da madeira de Cenostigma macrophyllum e da madeira de Eucalyptus sp.

pico de perda de massa é atribuído, principalmente, à decomposição da celulose e ocorreu entre $315^{\circ} \mathrm{C}$ e $390{ }^{\circ} \mathrm{C}$ (Figura 1- F4), onde 36,05\% da massa de madeira foi perdida. As curvas de TG e DTG não apresentaram picos específicos referentes à degradação da lignina da madeira.

A massa residual durante a análise termogravimétrica aos $400{ }^{\circ} \mathrm{C}, 500{ }^{\circ} \mathrm{C}$ e $600{ }^{\circ} \mathrm{C}$ foi, respectivamente, de $37,04 \%, 30,25 \%$ e $24,16 \%$ da massa seca inicial. Aos $450{ }^{\circ} \mathrm{C}$, temperatura final média nos fornos industriais de biorredução, a massa residual foi de 33,36\% da massa seca inicial. Estes rendimentos são inferiores aos observados na carbonização (Tabela 1).

A madeira de C. macrophyllum apresenta perfil termogravimétrico mais resistente à decomposição térmica do que a madeira da espécie utilizada como referência (Eucalyptus sp.). A perda de massa do eucalipto entre $315{ }^{\circ} \mathrm{C}$ e $390{ }^{\circ} \mathrm{C}$ (região atribuída, principalmente, à decomposição da celulose) é 38,72\% superior à da madeira do caneleiro. Foi observada massa residual $50,81 \%, 54,51 \%, 56,97 \%$ e $61,82 \%$ superior para madeira de C. macrophyllum, nas temperaturas de $400{ }^{\circ} \mathrm{C}, 450{ }^{\circ} \mathrm{C}, 500{ }^{\circ} \mathrm{C}$ e $600{ }^{\circ} \mathrm{C}$, respectivamente.

Tabela 2. Perda de massa e massa residual da madeira de Cenostigma macrophyllum (Can) e Eucalyptus sp. (Euc) durante análise termogravimétrica.

\begin{tabular}{cccccccc}
\hline \multirow{2}{*}{$\begin{array}{c}\text { Espécie } \\
\text { lenhosa }\end{array}$} & \multicolumn{2}{c}{$\begin{array}{c}\text { Perda de massa, em \% da massa seca, nos } \\
\text { intervalos de temperatura }\left({ }^{\circ} \mathbf{C}\right)\end{array}$} & \multicolumn{3}{c}{ Massa residual em relação à massa seca inicial (\%) } \\
\cline { 2 - 8 } & início-100* & $210-315$ & $315-390$ & $400^{\circ} \mathrm{C}$ & $450^{\circ} \mathrm{C}$ & $500^{\circ} \mathrm{C}$ & $600^{\circ} \mathrm{C}$ \\
\hline Can & 5,17 & 24,75 & 36,05 & 37,04 & 33,36 & 30,25 & 24,16 \\
Euc & 4,28 & 24,98 & 50,01 & 24,56 & 21,59 & 19,27 & 14,93 \\
\hline
\end{tabular}

*Em relação à massa úmida da amostra. 


\section{Discussão}

A elevada densidade apresentada pela madeira do caneleiro é vantajosa para a queima direta e biorredução, além de reduzir custos referentes ao transporte e armazenamento da biomassa e do carvão vegetal. Quanto maior a densidade deste bioredutor, maior será a quantidade de massa disponível para queima por unidade de volume, além de fornecer um carvão vegetal mais denso. No Brasil, as principais espécies utilizadas para produção de carvão vegetal são do gênero Eucalyptus, que possui densidade básica da madeira variando de 0,42 a 0,54 $\mathrm{g} \mathrm{cm}^{-3}$ (Silva et al., 2015; Soares et al., 2015; Trugilho et al., 2015; Boschetti et al., 2017), valores inferiores aos observados para a madeira do caneleiro $\left(1,200 \mathrm{~g} \cdot \mathrm{cm}^{-3}\right)$.

A densidade básica da madeira e a densidade relativa aparente do carvão vegetal resultante, geralmente, apresentam-se fortemente correlacionadas (Vale et al., 2010). Valores mais elevados de densidade relativa aparente são desejados, principalmente quando o carvão vegetal é destinado à siderurgia, pois quanto maior a densidade do carvão, melhor será a ocupação do mesmo no interior do alto forno, aumentando a eficiência do processo de conversão do minério de ferro.

A composição química, especialmente o alto teor de lignina, contribui positivamente para o rendimento em carvão vegetal (Soares et al., 2014) e para o poder calorífico da biomassa (Telmo \& Lousada, 2011).

Vale et al. (2010), estudando cinco espécies do Centro Oeste brasileiro, relataram teores de lignina variando de 25,16 a $32,31 \%$, e Castro et al. (2015), trabalhando com as espécies Hymenolobium petraeum, Dipteryx polyphylla, Hymenaea courbaril e Nectandra rubra, observaram teores de lignina de 31,77\%, 33,28\%, $31,88 \%$ e $33,63 \%$, respectivamente. Entre oito grupos de similaridade das características da madeira de clones de Eucalyptus ssp., foram observados teores médios de lignina entre 26,1\% e 30,3\% (Protásio et al., 2017). Os teores de lignina observados por esses autores são inferiores ao encontrado para o caneleiro (34\%), contudo, observa-se na literatura variação interespecífica do teor de lignina no xilema entre $15 \%$ e $40 \%$ (Novaes et al., 2010).

A quantidade de energia liberada pela madeira durante a queima afeta diretamente o rendimento energético da biomassa. Assim, elevados valores de poder calorífico superior (PCS) são desejáveis, principalmente quando a madeira é utilizada como lenha. O poder calorífico da madeira de caneleiro (4.845 kcal kg-1) foi superior aos valores comumente encontrados na literatura para as principais espécies do gênero Eucalyptus utilizadas para geração de energia, que se encontram na faixa de $4.300 \mathrm{Kcal} \mathrm{kg}^{-1}$ a $4.700 \mathrm{Kcal} \mathrm{kg}^{-1}$ (Protásio et al., 2013; Oliveira et al., 2014; Soares et al., 2014; Trugilho et al., 2015; Jesus et al., 2017). Santos et al. (2013), avaliando o potencial energético de espécies provenientes da Caatinga, encontraram valores médios de poder calorífico superior da madeira para as espécies Caesalpinia pyramidalis Tul. var. pyramidalis (4.442 kcal kg-1) e Commiphora leptophloeos (Mart.) J.B.Gillett $\left(4.478 \mathrm{kcal} \mathrm{kg}^{-1}\right)$ também inferiores aos observados para a madeira de caneleiro.

Os resultados de PCS obtidos no presente estudo podem estar relacionados ao teor de lignina presente na madeira. A lignina é uma macromolécula de origem fenólica que possui em sua composição cerca de $61 \%$ a $67 \%$ de carbono (Cortez \& Lora, 1997), o que contribui para o aumento do poder calorífico durante a queima da biomassa, já que a energia térmica liberada por um combustível depende principalmente da combustão do carbono e do hidrogênio, que estão presentes em sua estrutura (Santos et al., 2016).

O teor de extrativos também contribui para o aumento do PCS, principalmente aqueles de natureza aromática. A lignina e os extrativos possuem menos oxigênio em sua composição, quando comparados com os polissacarídeos (hemiceluloses e celulose). Além disso, esses componentes do lenho possuem estruturas complexas com mais carbono, liberando assim maiores quantidades de energia durante a combustão (Silva et al., 2014).

A redução no rendimento gravimétrico em carvão (RGC) observada entre as temperaturas de $400{ }^{\circ} \mathrm{C}$ e $600{ }^{\circ} \mathrm{C}$ ocorreu devido à perda de massa resultante da degradação térmica dos constituintes do lenho à partir do incremento da temperatura final de carbonização. Resultado similar foi observado por Azevedo et al. (2013), que trabalhando com clones híbridos de Eucalyptus sp., submetidos às temperaturas finais de $450{ }^{\circ} \mathrm{C}, 700{ }^{\circ} \mathrm{C}$ e $900{ }^{\circ} \mathrm{C}$ concluíram que a temperatura final de carbonização influenciou no RGC, pois quanto maior a temperatura de pirólise, menor foi o rendimento em carvão.

Ao avaliarem o potencial energético de cinco espécies de ocorrência do cerrado brasileiro, Costa et al. (2014), 
observaram valores de RGC variando entre $30,88 \%$ e $34,36 \%$, para carbonizações realizadas a $450{ }^{\circ} \mathrm{C}$. Valores inferiores aos observados para a carbonização realizada a $500{ }^{\circ} \mathrm{C}$ no presente estudo (36\%). Os elevados valores de RGC observados podem estar relacionados ao alto teor de lignina (34\%) e ao elevado valor de densidade básica da madeira $\left(1,200 \mathrm{~g} \mathrm{~cm}^{-3}\right)$, pois há correlação positiva entre o teor de lignina e a densidade básica da madeira e o RGC (Soares et al., 2014). Di Blasi et al. (1999), ao estudarem espécies nativas da região norte do Brasil, observaram maiores RGC de espécies ricas em extrativos. Assim, o elevado conteúdo destes componentes secundários observado para a madeira de caneleiro $(9 \%)$ pode ter contribuído para os altos rendimentos em carvão vegetal.

A redução do teor de materiais voláteis observada entre as temperaturas de $400{ }^{\circ} \mathrm{C}$ e $600{ }^{\circ} \mathrm{C}$ ocorreu simultaneamente ao aumento no teor de carbono fixo, pois à medida que os componentes orgânicos do lenho são degradados e volatilizados, há concentração de carbono no carvão vegetal.

O comportamento de redução no teor de voláteis e aumento no carbono fixo foi similar ao encontrado por Trugilho \& Silva (2001), que trabalhando com amostras de Hymenaea courbaril carbonizadas a temperaturas variando de $300{ }^{\circ} \mathrm{C}$ a $900{ }^{\circ} \mathrm{C}$, observaram redução de $92,4 \%$ no teor de materiais voláteis e aumento de $81,2 \%$ no teor de carbono fixo.

O aumento no PCS com o incremento da temperatura final de carbonização está relacionado ao acréscimo do teor de carbono fixo e volatilização, principalmente de oxigênio, que é um elemento indesejado para a utilização energética do carvão vegetal (Protásio et al., 2013).

O perfil termogravimétrico para a madeira do caneleiro é aquele tipicamente observado para outras amostras de madeiras, sob atmosfera inerte (Yang et al., 2007; Bianchi et al., 2010; Elyounssi et al., 2012; Poletto et al., 2012; Pereira et al., 2013a).

As faixas de temperatura da decomposição térmica dos constituintes da madeira (hemiceluloses, celulose e lignina) se sobrepõem em determinados pontos, dificultando a determinação exata da faixa de temperatura correspondente à perda de massa de cada um destes componentes no material lignocelulósico (Chen \& Kuo, 2010, Sebio-Puñal et al., 2012; Wang \& Howard, 2018). No entanto, estudos sobre o comportamento termogravimétrico destes compostos, de forma individual, permite identificar os picos onde ocorre, principalmente, a degradação das hemiceluloses e celulose.

Yang et al. (2007) verificaram a perda de massa da hemicelulose comercial (xilana) de forma mais acentuada entre $220^{\circ} \mathrm{C}$ e $315^{\circ} \mathrm{C}$ e relataram degradação da celulose comercial entre $315^{\circ} \mathrm{C}$ e $400{ }^{\circ} \mathrm{C}$. A perda de massa da lignina comercial ocorreu em uma ampla faixa de temperatura (de $160{ }^{\circ} \mathrm{C}$ a $900{ }^{\circ} \mathrm{C}$ ) e não apresentou um pico de reação definido. Estes resultados corroboram com as fases de volatilização dos constituintes do lenho do caneleiro (Figura 1).

Os intervalos de temperatura correspondentes à decomposição térmica dos componentes estruturais da madeira, observados neste estudo, são semelhantes aos obtidos para o material lignocelulósico investigado por diversos autores (Bianchi, et al., 2010; Pereira et al., 2013a; Cao et al., 2016; Wang \& Howard, 2018) onde não é possível identificar a região em que ocorre a maior taxa de volatilização da lignina. Por ser uma macromolécula de estrutura amorfa, com elevado grau de aromaticidade e que apresenta heterogeneidade quanto à força das ligações intramoleculares (Sarkanen \& Ludwig, 1971), a lignina não apresenta uma faixa de temperatura de degradação térmica definida, como ocorre com a holocelulose.

Em estudo termogravimétrico com 7 clones de Eucalyptus ssp., foi observada máxima massa residual aos $450{ }^{\circ} \mathrm{C}$ de $23 \%$ (base massa seca) (Araújo et al., 2016), valor inferior ao apresentado pela madeira do caneleiro, nas mesmas condições de pirólise (27,89\%). O perfil termogravimétrico do lenho de C. macrophyllum também apresentou maior resistência à decomposição térmica do que àquela verificada para Schizolobium amazonicum (Vidaurre et al., 2012) e Eucalyptus spp. (Pereira et al., 2013a), o que pode ser atribuído à composição química do caneleiro, especialmente o conteúdo de lignina e extrativos.

A lignina é o componente da biomassa que apresenta maior resistência à degradação térmica e o teor de extrativos solúveis em etanol da madeira representa um importante papel na decomposição térmica do lenho (Sebio-Puñal et al., 2012; Wang \& Howard, 2018). O conteúdo destes componentes também contribuiu para a menor volatilização da madeira em estudo (a partir dos $315^{\circ} \mathrm{C}$ ), em relação à biomassa de referencia (eucalipto), que apresentou teor de lignina 0,17 vezes inferior ao do caneleiro $(29 \%)$ e teor de extrativos solúveis em etanoltolueno, 4 vezes inferior $(2,19 \%)$. 
A divergência dos rendimentos da fração sólida da pirólise (Tabelas 2 e 3) se deve, principalmente, ao tamanho das partículas utilizadas nestas análises. A termogravimetria é realizada com pequena quantidade em massa do pó fino (200-270 mash) da madeira, enquanto na carbonização em forno mufla empregamse amostras sólidas e cerca de $500 \mathrm{~g}$ de massa. Nas partículas sólidas, a transferência de calor é mais lenta, a área superficial é menor e a liberação dos gases é prejudicada, de forma que uma fração do material volátil fica retida nos poros da madeira, elevando o rendimento gravimétrico do processo de carbonização em relação àquele verificado na termogravimetria. A resistência à degradação térmica verificada na madeira do caneleiro durante a análise termogravimétrica e na pirólise em forno mufla reafirma a qualidade desta espécie para o uso energético.

\section{Conclusões}

A densidade básica, o teor de lignina, o poder calorífico da madeira e os rendimentos em massa da fração sólida da pirólise indicaram viabilidade do uso da madeira de Cenostigma macrophyllum Tul (caneleiro) para geração de energia térmica, pois apresentaram valores consideravelmente superiores a outras espécies comumente utilizadas para esta finalidade.

A temperatura da carbonização afetou a qualidade do carvão vegetal. O rendimento gravimétrico em carvão e o teor de materiais voláteis reduziram com o aumento da temperatura de pirólise, resultado contrário foi observado para o teor de carbono fixo e o poder calorífico superior. Desta forma, se faz necessária a avaliação da temperatura final de pirólise para produção comercial de carvão vegetal, a fim de manter o equilíbrio entre o rendimento da fração sólida e a qualidade do material combustível resultante.

Estudos sobre técnicas de cultivo e manejo da Cenostigma macrophyllum são indicados para garantir o uso sustentável da espécie.

\section{Agradecimentos}

Os autores agradecem ao CNPq, CAPES e FAPEMIG pelo auxílio financeiro concedido na realização do trabalho.

\section{Referências}

American Society For Testing and Materials. Standard method for chemical analysis of charcoal. Philadelphia, 1982.

Araújo, A. C. C. et al. Efeito da relação siringil/guaiacil e de fenóis derivados da lignina nas características da madeira e do carvão vegetal de Eucalyptus spp. Scientia Forestalis, v. 44, n. 110, p. 405-414, 2016. DOI: 10.18671/scifor.v44n110.13

Associação Brasileira de Normas Técnicas. NBR 8112: carvão vegetal: análise imediata. Rio de Janeiro, 1986.

Associação Brasileira de Normas Técnicas. NBR 8633: carvão vegetal: determinação do poder calorífico. Rio de Janeiro, 1984.

Associação Brasileira de Normas Técnicas. NBR 11941: madeira: determinação da densidade básica. Rio de Janeiro, 2003.

Associação Brasileira de Normas Técnicas. NBR 14660: madeira amostragem e preparação para análise. Rio de Janeiro, 2004.

Azevedo, C. H. S. et al. Influência da temperatura final de carbonização e da taxa de aquecimento no rendimento gravimétrico e teor de cinzas do carvão de Eucalyptus urophylla x Eucalyptus grandis. Enciclopédia biosfera, v. 9, n. 16, p. 1279-1287, 2013.

Bailis, R. et al. Innovation in charcoal production: a comparative life-cycle assessment of two kiln technologies in Brazil. Energy for Sustainable Development, v. 17, n. 2, p. 189-200, 2013. DOI: 10.1016/j.esd.2012.10.008.

Bianchi, O. et al. Avaliação da degradação não-isotérmica de madeira através de termogravimetria - TGA. Polímeros, v. 20, n. 5, p. $395-$ 400, 2010. DOI: 10.1590/S0104-14282010005000060.

Boschetti, W. T. N. et al. Propriedades do carvão vegetal produzido com madeira de reação proveniente de árvores inclinadas por ventos. Revista Árvore, v. 41, n. 6, p. 1-7, 2017. DOI: 10.1590/1806 90882017000600001.

Cao, L. et al. Thermogravimetric characteristics and kinetics analysis of oil cake and torrefied biomass blends. Fuel, v. 175, p. 129-136, 2016. DOI:10.1016/j.fuel.2016.01.089.

Castro, J. P. et al. Uso de espécies amazônicas para envelhecimento de bebidas destiladas: análises física e química da madeira. Cerne, v. 21, n. 2, p. 319-327, 2015. DOI: 10.1590/01047760201521021567.

Castro, V. R. et al. Efeito da disponibilidade hídrica e da aplicação de potássio e sódio no crescimento em diâmetro do tronco de árvores de Eucalyptus grandis. Scientia Forestalis, v. 45, n. 113, p. 89-99, 2017. DOI: $10.18671 /$ scifor.v45n113.08.

Chen, W. H. \& Kuo, P. C. A study on torrefaction of various biomass materials and its impact on lignocellulosic structure simulated by a thermogravimetry. Energy, v.35, p. 2580-2586, 2010. DOI: 10.1016/j.energy.2010.02.054.

Cortez, L.A. \& Lora, E.S. Tecnologia de conversão energética da biomassa. EDUA/EFEI. Manaus, 1997. 527p. (Série sistemas energéticos II).

Costa, T. G. et al. Qualidade da madeira de cinco espécies de ocorrência no cerrado para produção de carvão vegetal. Cerne, v. 20, n. 1, p. 37-46, 2014. DOI: 10.1590/S0104-77602014000100005. 
Couto, A. M. et al. Qualidade do carvão vegetal de Eucalyptus e Corymbia produzido em diferentes temperaturas finais de carbonização. Scientia Forestalis, v. 43, n. 108, p. 817-831, 2015. DOI: $10.18671 /$ scifor.v43n108.7

Di Blasi, C. et al. Product distribution from pyrolysis of wood and agricultural residues: Indian engeneering. Chemistry Research, v. 38 , n. 12 , p. 2216-2224, 1999.

Elyounssi, K. et al. High-yield charcoal production by two-step pyrolysis. Journal of Analytical and Applied Pyrolysis, v. 87, n. 1, p. 138-143, 2010. DOI: 10.1016/j.jaap.2009.11.002.

Freitas, P. de C. et al. Efeito da disponibilidade hídrica e da aplicação de potássio e sódio nas características anatômicas do lenho juvenil de Eucalyptus grandis. Revista Árvore, v. 39, n. 2, p. 405-416, 2015. DOI: 10.1590/0100-67622015000200020.

Ghani, W.A.W.A.K. et al. Biochar production from waste rubberwood-sawdust and its potential use in $\mathrm{C}$ sequestration: Chemical and physical characterization. Industrial Crops and Products. Vol. 44, pg. 18-24, 2013. DOI.:10.1016/j.indcrop.2012.10.017

Goldschimid, O. Ultraviolet spectra. In: Sarkanen, K. V. \& Ludwig, C. H. Lignins: occurrence, formation, structure and reactions. New York: John Wiley \& Sons, 1971. p. 241-266.

Gomide, J. L. \& Demuner, B. J. Determinação do teor de lignina em material lenhoso: método Klason modificado. O Papel, v. 47, n. 8, p. 36-38, 1986.

Indústria Brasileira de Árvores. IBÁ: Indústria Brasileira de Árvores. Brasília, DF, 2017. 80 p. Relatório IBÁ 2016.

Jesus, M. S. et al. Caracterização energética de diferentes espécies de Eucalyptus. Floresta, v. 47, n. 1, p. 11-16, 2017. DOI: 10.5380/ rf.v47i1.48418.

Machado, R. R. B. et al. Árvores nativas para a arborização de Teresina, Piauí. Revista da Sociedade Brasileira de Arborização Urbana, v. 1, n. 1, p. 10-18, 2006.

Neves, S. C. G. \& Neves, E. Fazenda Aracaju: plano de manejo florestal. Cristino Castro, 2008. 53 p. Plano de Manejo Florestal Sustentável apresentado ao IBAMA, nº 2200.2.2009.00023.

Novaes, E. et al. Lignin and Biomass: A negative correlation for wood formation and lignin content in trees. Plant Physiology, v. 154, p. 555-561, 2010.

Oliveira, A. C. et al. Otimização da produção do carvão vegetal por meio do controle de temperaturas de carbonização. Revista Árvore, v. 37, n. 3, p. 557-566, 2013. DOI: 10.1590/S010067622013000300019 .

Oliveira, C. A. de C. et al. Potencial energético da madeira de Eucalyptus sp. em função da idade e de diferentes materiais genéticos. Revista Árvore, v. 38, n. 2, p. 375 -3 8, 2014. DOI: 10.1590/ S0100-67622014000200019.

Pereira, B. L. C. Estudo da degradação térmica da madeira de Eucalyptus através de termogravimetria e calorimetria. Revista Árvore, v.37, n.3, p.567-576, 2013.

Pereira, B. L. C. et al. Influence of chemical composition of Eucalyptus wood on gravimetric yield and charcoal properties. BioResources, v. 8, n. 3, p. 4574-4592, 2013 b.
Poletto, M. et al. Thermal decomposition of wood: Influence of wood components and cellulose crystallite size. Bioresource Technology, v. 109, p. 148-153, 2012. DOI: 10.1016/j.biortech.2011.11.122.

Protásio, T. P. et al. Classificação de clones de Eucalyptus por meio da relação siringil/guaiacil e das características de crescimento para uso energético. Scientia Forestalis, v. 45, n. 114, p. 327-341, 2017.

Protásio, T. P. et al. Potencial siderúrgico e energético do carvão vegetal de clones de Eucalyptus spp. aos 42 meses de idade. Pesquisa Florestal Brasileira, v. 33, n. 74, p. 137-149, 2013. DOI: 10.4336/2013.pfb.33.74448.

Queiroz, L. P. Leguminosas da Caatinga. Feira de Santana: Universidade Estadual de Feira de Santana, 2009. 467 p.

Santos, R. C. S. et al. Influência das propriedades químicas e da relação siringil/guaiacil da madeira de eucalipto na produção de carvão vegetal. Ciência Florestal, v. 26, n. 2, p. 657-669, 2016.

Santos, R. C. S.et al. Potencial energético da madeira de espécies oriundas de plano de manejo florestal no estado do Rio Grande do Norte. Ciência Florestal, v. 23, n. 2, p. 491-502, 2013. DOI: $10.5902 / 198050989293$.

Sarkanen, K. V. \& Ludwig, C. H. Lignins: ocurrence, formation, structure and reaction. New York: Wiley, 1971. p. 165-230.

Sebio-Puñal, T. et al. Thermogravimetric analysis of wood, holocellulose, and lignin from five wood species. Journal of Thermal Analysis and Calorimetry, v. 109, p. 1163-1167, 2012. DOI: $10.1007 /$ s10973-011-2133-1.

Silva, D. A. et al. Avaliação das propriedades energéticas de resíduos de madeiras tropicais com uso da espectroscopia NIR. Floresta e Ambiente, v. 21, n. 4, p. 561-568, 2014. DOI:10.1590/21798087.043414 .

Silva, D. A. et al. Propriedades da madeira de Eucalyptus benthamii para produção de energia. Pesquisa Florestal Brasileira, v. 35 n. 84 p. 481-485. 2015. DOI: 10.4336/2015.pfb.35.84.677.

Silva, D. A. et al. Avaliação das propriedades energéticas de resíduos de madeiras tropicais com uso da espectroscopia NIR. Floresta e Ambiente, v. 21, n. 4, p. 561-568, 2014. DOI: 10.1590/21798087.043414.

Soares, V. C. et al. Análise das propriedades da madeira e do carvão vegetal de híbridos de eucalipto em três idades. Cerne, v. 21, n. 2, p. 191-197, 2015. DOI: 10.1590/010477 60201521021294 .

Soares, V. C. et al. Correlações entre as propriedades da madeira e do carvão vegetal de híbridos de eucalipto. Revista Árvore, v. 38, n. 3, p. 543-549, 2014. DOI: 10.1590/S0100-67622014000300017.

Telmo, C. \& Lousada, J. Heating values of wood pellets from different species. Biomass and Bioenergy, v. 35, n. 7, p. 2634-2639, 2011.

Teresina. Decreto $\mathbf{n}^{\mathbf{0}} \mathbf{2 . 4 0 7}$, de 13 de agosto de 1993. Estabelece os símbolos municipais de Teresina, capital do Estado do Piauí. Disponível em: < http://semplan.teresinapi.gov.br/ simbolos-deteresina/ >. Acesso em 30 maio 2018.

Trugilho, P. F. et al. Características de crescimento, composição química, física e estimativa de massa seca de madeira em clones e espécies de Eucalyptus jovens. Ciência Rural, v. 45, n. 4, p. 661666, 2015. DOI: 10.1590/0103-8478cr20130625. 
Trugilho, P. F. \& Silva, D. A. Influência da temperatura final de carbonização nas características físicas e químicas do carvão vegetal de jatobá (Hymenaea courbaril). Scientia Agraria, v. 2, n. 1/2, p. 45-53, 2001. DOI: 10.5380/rsa.v2i1.976.

Vale, A. T. do et al. Relações entre propriedades químicas, físicas e energéticas da madeira de cinco espécies de cerrado. Ciência Florestal, v. 20, n. 1, p. 137-145, 2010. DOI: 10.5902/198050981767.

Vidaurre, G. B. Propriedades energéticas da madeira e do carvão de paricá (Schizolobium amazonicum). Revista Árvore, v. 36, n. 2, p. 365-371, 2012.

Vieira, R. da S. et al. Influence of temperature on products yield of Eucalyptus microcorys carbonization. Cerne, v. 19, n. 1, p. 59-64, 2016. DOI: 10.1590/S0104-77602013000100008.
Vilas Boas, M. A. et al. Efeito da temperatura de carbonização e dos resíduos de macaúba na produção de carvão vegetal. Scientia Forestalis, v. 38, n. 87, p. 481-490, 2010.

Wang P. \& Howard B. H. Impact of thermal pretreatment temperatures on woody biomass chemical composition, physical properties and microstructure. Energies, v. 11, n. 1, p. 1-25, 2018. DOI: 10.3390/ en 11010025.

Yang, H. et al. Characteristics of hemicellulos, cellulose and lignin pyrolysis. Fuel, v. 86, n. 12-13, p. 1781-1788, 2007. DOI: 10.1016/j. fuel.2006.12.013. 